\title{
HOW TO EFFECTIVELY BUILD MARKETING IN THE DIGITAL ERA ECONOMIES
}

\author{
Akmaral Orazymbetova ${ }^{1}$, Berik Bekmurzayev ${ }^{l}$, Akmaral Kazykeshvova ${ }^{2}$, Svetlana \\ Faizullina $^{3}$, Asel Kogabayeva ${ }^{l}$ \\ ${ }^{1}$ Al-Farabi KazNU, pr. al Farabi, 71, 050040 Almaty, Republic of Kazakhstan \\ ${ }^{2}$ Serikbayev East-Kazakhstan State Technical University, 070004, Ust-Kamenogorsk, \\ Kazakhstan \\ ${ }^{3}$ Abai Kazakh National Pedagogical University, 050000, Almaty, Kazakhstan
}

\begin{abstract}
The article describes the problems and criteria for the development of marketing in the era of the digital economy. In the structure of the digital economy, the process of modifying marketing into smart-marketing (digital-marketing) happens - work that allows the use of digital advanced technologies. Thus, by analyzing "Big Data" and applying other achievements of advanced technology, it is possible to influence the compilation of needs, as well as develop and promote value propositions for consumers on the market. The article uses methods general scientific method, i.e. analysis of world experience in transition to absolute digital economy, implementation of digitalization in all types of activities; philosophical method - is based on analytical and statistical conclusions about digitalization of economy and its impact on other activities; analogue method - the same forecasts about digitalization of marketing were taken from the theory of digital economy and its direction. As a result, based on the SWOT analysis, leaning on the strengths, weaknesses, threats and opportunities, it is possible to understand that the digital economy undoubtedly affects marketing.
\end{abstract}

\section{Introduction}

The research methodology was of analytical and statistical nature, with an emphasis on studying changes in marketing instruments at this stage. In the new period of technological cycle, the modern society faces cardinal changes in all spheres of activity. Digital technologies thanks to their unique capabilities have greatly increased the information field of people and enterprises, reduced the cost of searching and processing information. The new evolutionary wave of digitalization has demanded changes in the economy, which has led to the emergence of the term "digital economy". Based on digital economy theory, the concept of "digital marketing" has become an integral part.

The main purpose of the scientific article is the effective building of marketing in the era of digital economy. In order to achieve this goal the following tasks were identified:

\footnotetext{
${ }^{*}$ Corresponding author: ertis_economika@mail.ru
} 
- research of smart marketing in the era of digital economy development;

- studying the development and promotion of modern offers in the market using advanced technology;

- identification of opportunities for globalization of digital marketing tools around the world.

It is obvious that digitalization of economy and development of virtual space have become integral features of the economies of the leading countries, affecting all spheres of life. There are increasing processes in the world that require fresh layouts and modification of the eyes on marketing management. The formation of information society, smart economics, globalization processes cause the need for digital marketing, with this paradigm of digital marketing every day is developing, forming the circumstances for the successful establishment and competitive positioning of business.

Digital marketing is marketing that provides interaction with customers and business partners with the introduction of digital information, communication and digital technologies. In a broader sense, under digital marketing we are aware of the implementation of advertising work with the introduction of digital information and communication technologies. Internet marketing is considered an integral part of digital marketing, which is developed together with it.

\section{Literature review}

In order to carry out marketing research, scientific works, scientific bibliographies of theoretical and empirical nature were studied. The use of digital technologies in marketing was considered by Kent Wertime and Jan Fenwick (2010) in the book "Digital Marketing", where they accurately noted the value of digital marketing for marketers. [1]

M. Castells (2004) wrote about the power of information technology, which is important for the development of digital economy. He highlights two distinctive features of the new

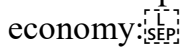

- productivity depends on the achievement of science and technology, as well as the quality of information and management;

- there is a shift of interests of producers and consumers from material production to information activity;[2]

The marketing complex and its tools clearly show the development of marketing. Advantages and disadvantages of Internet marketing and its possibilities were considered by L. M. Kapustina and I. D. Mosunov (2014) from the position of the $4 \mathrm{P}$ marketing complex.[3].

The originality of these technologies has taken all activities to a new level. About this Nadtoka T.B. and Matveev N.B. (2017) says that the digital economy has greatly changed the standard approaches to business management, that unprecedented forms have entered the market: "Uber, the largest taxi service in the world, has no own vehicles. Facebook, the world's most popular media company, does not create content".[4]

The aim of the article is to show how the development of digital economy influences marketing and a vivid example is the statement of Ziyadin S.T. (2018) that digital economy works through e-commerce with electronic work and management processes, interacts with its partners, clients and translates through the Internet and digital technologies. [5]

However, in most cases, in the works of designated researchers considered digital technology as applied to individual components or their combination in an ensemble of marketing, for example, working with customers or advertising products. Even despite the number of papers written and conducted, the study of digital technology in marketing is not enough. 
Keen, Peter G., Ron Mackintosh, and Mikko Foreword By-Heikkonen wrote that technology was meritocratic in that many countries lacked the infrastructures and capital required to put personal computers in schools and homes or to make it practical for businesses to exploit electronic commerce in the same way as in advanced economies.

Lazovic, Vujica, and Tamara Đuričković researched the digital economy brings with it a number of opportunities, but also new challenges and rules of the game in the global market.

Leeflang, Peter SH, Peter C. Verhoef, Peter Dahlström, and Tjark Freundt wrote that a great deal of attention has been focused on the tremendous opportunities digital marketing presents, with little attention on the real challenges companies are facing going digital.

Duguleana, L. and Duguleana C. researched the components of mix marketing get new meanings and the new marketing communication channels offer new ways of advertising and new indicators to measure the effects.

Nudurupati, Sai S., Sofiane Tebboune, and Julie Hardman wrote the rate of change in the world is increasing in both scope and magnitude by rapidly developing digital technologies Stanković, Jelena, and J. Djorđević-Boljanović wrote the digital transformation process covers changes in four key business areas, "4c's" of digital transformation, which are commerce, content, business community and collaboration. Besides the evolution of marketing channel intermediaries, digital transformation process affects the roles and behavior of clients while doing their business transactions and communication.

Owyang, Jeremiah, Christine Tran, and Chris Silva wrote that social technologies radically disrupted communications, marketing, and customer care. With these same technologies, customers now buy products once and share them with each other.

\section{Methodology}

According for preparing this scientific article there were used the next methods of research:

- general scientific method: analyzing the world experience of transition to an absolute digital economy, introducing digitalization in all activities;

-philosophical method: based on analytical and statistical conclusions about the digitalization of the economy and the impact on other activities;

-analogical method: the same predictions about digitalization of marketing were taken from the theory of the digital economy and its direction.

\section{Results and discussions}

Digital marketing in the broadest sense is interpreted as a management technology aimed at increasing competitiveness and ensuring economic growth. So the digital economy has a direct link in web marketing development. By the concept of digital marketing, we mean modern marketing using digital technology to achieve more global and broader results in less time and cost. [6]

For example, the article will study the impact of the digital economy on marketing in the context of the marketing complex (4P), as a reasonable improvement of economic activity using digital technology. The appearance of online retail sites characterizes the need for the cost of rent and maintenance of shop windows, shelving and other things. Electronic platforms, websites and social media tools have been replaced.[7] To make a more accurate comparison, for example, the volume of sales in an online store worldwide increased by $6 \%$ from 2017 to 2019 . The volume is projected to reach 2 trillion dollars in 2020. Figure 1 shows an approximate increase in sales in the coming years. 
These statistics and forecasts are a prime example of the value of web marketing and the positive impact that the digital economy has on marketing development. At the end of the twentieth century, namely in the 70's, David Ogilvy said that direct targeted communications have gained a rapid spread in marketing activities, and all speaks of their accelerated development now and in the future. At the same time, E. Nay said that direct marketing would be the most effectively developing area of marketing in the coming decade. The current level of development of direct marketing shows that the above was true and their research showed the exact future in marketing activities.

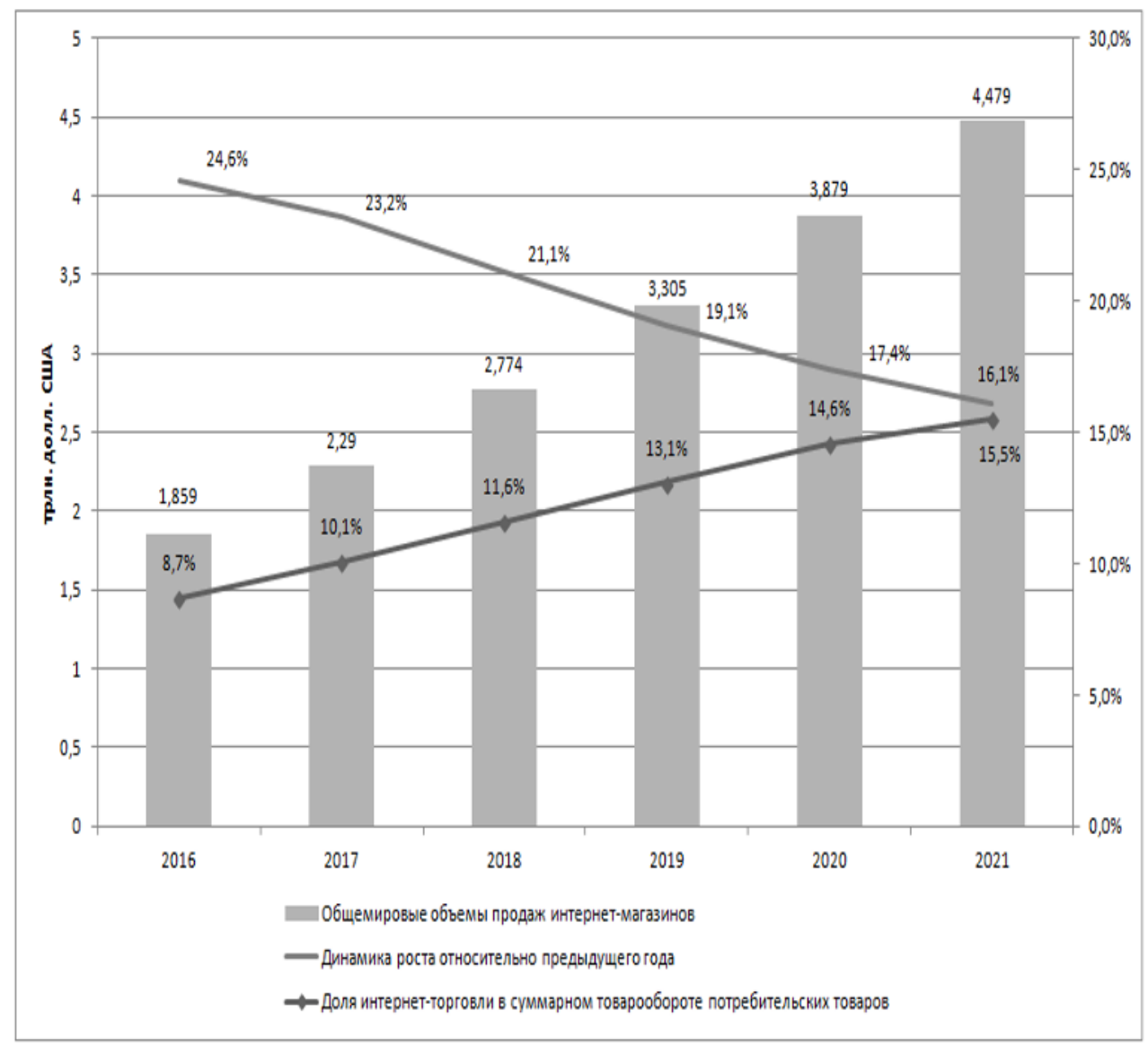

Fig. 1. Predicted dynamics of the world e-commerce [8].

Web marketing uses all digital channels (are direct channels), connecting the Internet and all kinds of devices that give access to it, mobile devices, absolutely all modern devices that have the ability to collect information and transfer it to other media, which accordingly speeds up the process of processing data information. [10]

As Roger Best's book says, digital marketing is an excellent tool for building a direct channel to potential consumers without third parties. Without digital marketing, building a direct channel is not profitable, as working with major customers takes up most of the time and money. He says that electronic marketing has perhaps the greatest potential to attract new consumers from all channels. [11] 
Digital media are targeted channels that allow marketers to work with a continuous two-way personalized dialogue with each consumer. This method is based on the use of information obtained as a result of previous interactions with the customer to serve the following contacts.[12] The differences between digital media and traditional ones are very different, important descriptions of these media channels are shown in Table 1.

Table 1. Differences between media channels in marketing [13].

\begin{tabular}{|l|l|l|}
\hline & Traditional channels & Digital channels \\
\hline Customers & Observers & Stakeholders \\
\hline Influence & Frequency Dependence & Interactive Dependence \\
\hline Means of mass communication & Languages & Address channels \\
\hline Time zone attachment & Time zone binding & No time zone reference \\
\hline Strategy & "Push" strategy & "Pull strategy \\
\hline Performance Control & $\begin{array}{l}\text { Data is not always available, } \\
\text { analysis at the end of the } \\
\text { campaign. }\end{array}$ & $\begin{array}{l}\text { Data availability, online } \\
\text { measurements }\end{array}$ \\
\hline
\end{tabular}

The digital environment produces a huge amount of data, ranging from clickstream data (fast data exchange), customer reviews and ratings, blogs, tags and social interactions data, to customer responses to marketing activities and information about employees and competitors. This data is very informative for the firm to understand online client behavior, develop marketing strategies, and evaluate the effectiveness of their actions and tactics in relation to marketing results.

Early digital environment studies conducted by Hoffmann and Novak (1996) suggested a structural model of consumer navigation in the digital environment, including the notion of flow. [14]

The model was later formalized using quantitative analysis to correlate the model with specific consumer behavior on the Internet (Novak, Hoffman, \& Yung, 2000). Bucclean and Sismayro (2003) modeled visitor behavior when browsing a website and examined visitors' decisions to continue browsing more pages (or exit) and the length of time spent on websites. [16] The browsing dynamics are consistent with blocking and sticking to a website and teaching the visitor how to re-visit it. Using similar data, Sismayro and Bucklin (2004) modeled customer buying behavior on the Internet. [17] The main conclusions were that the number of repeat visits did not indicate a propensity to buy, and the availability of sophisticated decision-making tools did not guarantee conversion.

Moe (2003) used the data to empirically test the typology of shop-accesses that varied according to the customer's purpose - buying, browsing, searching, or gaining knowledge - and was able to classify the visits using behavioural data.[18] This classification helps to identify and target potential customers and to develop a more effective and personalised advertising message. Clickstream analysis is widely used in marketing research, and Booklin and Sismeiro (2009) provided an overview of the benefits and limitations of such data for research purposes and how best to use it. [19]

Another rich source of data is social interactions on social networks. Trusov, Bodapati and Baklin (2010) focused on identifying influential members of a social network - influential individuals who could then be targeted by a firm hoping to spread their message.[20] The authors developed an approach to identify specific users who have significant influence on the activities of others, using longitudinal records of member login activity.

Katona, Zubsik and Sarvari (2011) studied how product/service acceptance depends on network effects and personal influences.[21] Using network metrics, their 
model focused on predicting the next set of followers defined by the set of previous followers. Such techniques are of practical value for viral marketing by identifying network relationships between potential clients.

There are two types of special actions for digital marketing strategies: (i) media advertising and (ii) SEO (search engine optimization) and SEM (search engine marketing).

Display type actions are effective because of the large amount of segmentation used and the impact on the direct audience. These actions are called RTB actions, although they are usually known to professionals as display type advertising. Marketing in search engines can also be considered an effective strategy because it makes the most profit in the digital market in Spain. The most effective strategies are organic search engine positioning and sponsored searches on search engines and blogs. Loyalty actions (recurring customer enquiries) have two main categories of actions because of their effectiveness: after-sales service and postal marketing, after-sales service and postal marketing.

Using this type of action, the business allows customers to test new products or services using a "free usage" strategy so that the customer trusts the business and tries new experiences for free, although the long-term strategy is to turn this user into a premium user.

Email marketing sends for loyalty actions (regular customer requests) email marketing strategies are most effective because they offer discounts and personalized promotions for each of the segmented groups in the database.

The theoretical basis was confirmed by the feedback received from the group of experts, and then the following stages of the Delphi process began. The group of experts who agreed to participate consisted of 18 experts from the digital marketing industry. The conclusions drawn from the information and comments provided by the expert group are set out below:

The database actions are aimed at attracting potential customers to contract with B2C enterprises. The experts suggest collecting potential customers through Twitter and Email marketing campaigns due to the nature of these social networks. In addition, Leads databases for B2C companies should use two main channels for obtaining Leads: acquisition of quality databases and creation of a client database, which the company has.

The social networks that are most useful for obtaining information about potential customers for B2C companies are Facebook and Twitter because they are social networks that exchange content non-aggressively through advertising campaigns that provide the user with interesting information and content. The social network, which a group of experts preferred for Loyalty actions (actions to turn clients into regular / regular clients) for B2C, was YouTube. It is a social network that has the best ratio of categorization and segmentation of content because it uses visual advertisements related to the content that the user is viewing. (Lopez G., David L., 2019)[22].

The two key marketing elements on which the firm seeks to maintain a sustainable competitive advantage are its brand and its clients. I have focused on recent research related to these elements of marketing strategy - and how the firm should strategically manage its brand and clients in an ever-changing digital landscape.

The introduction of new channels, new devices for shopping and new customer interactions requires a new understanding of customer management and brand management, and also requires firms to redefine marketing set metrics and CRM metrics. For example, Hanleyn (2013) studied the impact of social interactions on customer churn and reported that the level of churn is higher for a customer who is associated with previously repressed people.[23]

Scientists have discussed how social media will change "social CRM" strategies and emphasized that consumer value includes not only the value based on the purchase, but also the value of their social impact. Given that digital technologies have a significant 
impact on some elements of consumer value, such a study requires a more comprehensive definition of consumer value.[24].

Let's build a SWOT analysis based on these facts:

Table 2. SWOT analysis

\begin{tabular}{|c|c|}
\hline Strength & Weakness \\
\hline $\begin{array}{l}\text {-Easy to navigate and attract more audiences at a } \\
\text { lower price. } \\
\text {-Campaigns can be easily set up and made more } \\
\text { are targeted according to our business } \\
\text { requirements. } \\
\text {-as the world is increasingly dependent on the } \\
\text { Internet, it helps to... } \\
\text { business to get out and get in touch with people } \\
\text { on } \\
\text { on a larger scale. } \\
\text {-Saves a lot of money compared to the traditional } \\
\text { way. } \\
\text { marketing as cheaper and more efficient. } \\
\text { not worth a lot of money. }\end{array}$ & $\begin{array}{l}\text {-High chances of failure of digital marketing } \\
\text { campaigns due to the confusion of many } \\
\text { different marketing options. } \\
\text { - Keep up with new trends and technologies. } \\
\text {-The need for a deep understanding of human } \\
\text { behavior change } \\
\text { and demands. } \\
\text {-If your brand or product does not meet the needs } \\
\text { of users, } \\
\text { then the chance to get bad reviews in public is } \\
\text { very... } \\
\text { high, which in turn can damage the reputation. }\end{array}$ \\
\hline $\begin{array}{l}\text { Opportunity } \\
\end{array}$ & $\begin{array}{c}\text { Threat } \\
\end{array}$ \\
\hline $\begin{array}{l}\text {-There are more and more jobs for young people, } \\
\text { as this area is only growing and the number of } \\
\text { professionals is decreasing. } \\
\text { - Increase the reach of your brand, resulting in } \\
\text { direct profits. } \\
\text { - There are many ways that owners earn money } \\
\text { beyond their core business, such as providing } \\
\text { space for website advertising, affiliate marketing } \\
\text { in e-commerce, etc. }\end{array}$ & $\begin{array}{l}\text {-And the ever-changing trends in different areas } \\
\text { of marketing } \\
\text { and constantly changing search engine rules to } \\
\text { optimize content require constant awareness, } \\
\text { which is very difficult. } \\
\text {-Storing data with complete security is still a big } \\
\text { question. } \\
\text {-Inadequate data analysis can lead to destructive } \\
\text { results, which are common in many companies. }\end{array}$ \\
\hline
\end{tabular}

On the basis of the SWOT analysis built, we can understand that the digital economy undoubtedly influences marketing in a good way and will help to achieve the main goal - to digitalize the whole of Kazakhstan in all areas of activity. And marketing is undoubtedly improving towards development and the main attention is taken by marketing tools in the digital form.

The main focus in brand management is on understanding how the brand is created, changed and strengthened in the digital landscape. Hewitt (2016) described how social media sites have created reflective 'echo-reactions' to communicate with brands, creating complex loops of feedback between corporate communications, media and usergenerated social networks. Butra and Keller (2016) provided an overview of these synergies in the context of brand communication.[26] Brand positioning strategies can be influenced by search engine marketing (SEM) and search engine optimization strategies. Because SEM and SEO are adapted and applied to mobile devices, voice search, application search, and chat trading, more factors and indicators need to be considered when designing a branding strategy. Hansens and Pauels (2016) discussed in detail the indicators and measures needed to monitor the implementation of strategies and to determine the value of marketing to the firm.[27] 
As new digital devices and technologies develop, future research should focus on how firms can use these developments to create sustainable competitive advantages, increase market share and increase client capital and brand.

Based on all the above, we can say that fresh technologies, resources and services of online activities are used in marketing and affect the formation of advertising information systems. Collective portals and other Internet resources of the company are considered to be tools of external and internal advertising communications, branding, give abilities for electronic business, management of relations with customers and business partners, management of business processes of marketing, formation of professional public networks and information communities for communication.

The value proposition of the firm has an opportunity to be significantly expanded by connecting additional Internet services. Internet portal gives wide abilities for marketing of partner relations: roles of buyers and business partners in development of value offer of the firm, formation of loyalty programs, etc.

With the introduction of such new technologies, interactive and database marketing is successfully developed, allowing to move from global marketing to motivated marketing and to think of individual customers. With the development of technologies and services online advertising information systems are increasingly used not only for information assistance in making marketing conclusions, but also to automate advertising business processes.

Examples include web surveys; automatic direct marketing campaigns in online ways of emailing, web-channels and other tools; self-generated web content syndication; automatic management of media and context marketing campaigns in Online, management of scattering in the electronic market (automated interaction with online trading platforms and other partners), dynamic management of pricing based on data about online buyers and almost all of the above.

Online is actively used in initial and secondary advertising studies. Mobile Internet technologies, resources and services are developing rapidly.[29].

In this way, it can be noted that the importance of using digital tools in the process of promoting a product or service in the current market is determined by their unique abilities, which are due to modern advances in science and technology.

\section{Conclusion}

Based on the results of the study, the following facts can be highlighted:

-The global structure of information technology for the better, which has become the main factor in the development of the digital economy, has made a greater impact on marketing activities and marketing tools, changing traditional approaches to the latest types of activities;

- reduced marketing costs thanks to digital technologies;

- saving time and effort in processing and searching for big information (Big Data) to work with marketing tools;

- digital (online) integration of the entire population, regardless of material income, the inclusion of society in the information space, which depends on digital solutions and digital literacy.

Summing up the findings of the study, we are convinced that marketing in the era of the digital economy, as well as all activities in the present time need to use modern formats of the global trend using .

Digital marketing has become such a powerful advertising network that with Google's "Double Click" strategy for the Internet, the world has become very closely connected to 
every convenient place. With digital marketing, campaigns to promote any product over the Internet have become very cost-effective and convenient.

With the digital marketing feature, it's easy for advertisers to find out how many times and how long a campaign has been shown online, as well as how many people have seen the campaign, how many responses have been received and how many purchases have been made online. Thanks to this modern technology, marketing of any specific product becomes easier, the convenience to consumers becomes possible, and the organization also gets a huge profit.

Improved versions of this digital marketing are broadband internet, Wi-Fi network and mobile phone access. The use of these methods has increased dramatically around the world. According to the latest report, internet usage has increased by $10 \%$ worldwide from January 9 to 10 .

Management attitudes have changed. They have shifted from traditional forms of advertising to digital marketing. Billions of dollars were spent by organizations on digital marketing to promote their advertising campaigns. They are getting huge benefits from digital marketing and making high profits.

For example, social networks are now not only entertainment, but have become a platform for trade or brand promotion. It is in social networks that we find data on the needs and opinions of potential consumers.

And this is only one way to use the opportunities and tools of the digital economy. Absolutely digitalized state and government, people service centers, educational institutions, marketing activities and many other areas are moving to a new level, engaging in evolution. Competition in the current market environment contributes to the development of digital technologies, which makes it important to use digital tools in competition and in the process of promotion and positioning of goods and services.

At the moment, marketing in the era of digital economy has not yet reached the evolutionary and newest peak, which indicates further development of marketing (marketing tools, technologies, strategy and fully activity) in the direction of digital technologies.

\section{References}

1. Wertime, K., \& Fenwick, me. Digital marketing, 2010

2. Castells, M. The Information Age. URL: http://www. telecomlaw. ru/studyguides/Kastel. Pdf, 2004

3. Kapustina, L.M., \& Mosunov, I.D. Complex "4P" and model "6I" of internet marketing. Journal of New Economy, (6 (56)), 2014

4. Nadtoka, T.B., \& Matveev, N.V. Transformation of marketing activities of enterprises in the digital economy. Bulletin of the Institute for Economic Research, (4 (8)), 2017

5. Ziyadin, S., Ermekbaeva, B., Supugaliyeva, G., Doszhan, R. Transformation of basic indicators of socio-economic processes in the digital economy, IBIMA (2018)

6. Vlasova, N. Y., \& Kulikova, E. S. Marketing of the territory in the conditions of formation of digital economy. Journal of New Economy, 19(3), 2018

7. Nadtoka, T.B., \& Matveev, N.V. Transformation of marketing activity of enterprises in conditions of digital economy formation. Bulletin of the Institute for Economic Research, (4(8)), 2017

8. eMarketer: Retail TrendPack: The Latest Data and Analysis for Retail Ecommerce [Electronic Resource] / eMarketer Ink. - - 2017. - URL: https:// www.emarketer.com / Report/Retail - 2017. 
9. Polikarpov, A.N. Globalization of Business and Internet Marketing (Doctoral dissertation, [All-Russia Scientific and Research Conjuncture. in-t.]), 2004

10. Danko, T.P., \& Kitova, O.V. Issues of Digital Marketing Development. Problems of Modern Economy, (3 (47)), 2013

11. Best, P. Marketing from the consumer. "Mann, Ivanov \& Ferber, 2008

12. Trubnikova, N.V. Creativity in Post-Information Dimension: Marketing Aspects. Vestnik of the Peoples' Friendship University of Russia. Series: Economics, (2), 2016

13. Artamonova, O. V. Relevance of the use of digital-tools in the promotion of the product in the modern market. Young scientist, (10), 184-187.Hoffman, D. L., \& Novak, T. P. (1996).

14. Marketing in hypermedia computer-mediated environments: Conceptual foundations. Journal of marketing, 60(3), 50-68, 2017

15. Novak, T. P., Hoffman, D. L., \& Yung, Y. F. Measuring the customer experience in online environments: A structural modeling approach. Marketing science, 19(1), 22-42, 2000

16. Bucklin, R. E., \& Sismeiro, C. A model of web site browsing behavior estimated on clickstream data. Journal of marketing research, 40(3), 249-267, 2003

17. Sismeiro, C., \& Bucklin, R. E. Modeling purchase behavior at an e-commerce web site: A task-completion approach. Journal of marketing research, 41(3), 306-323, 2004

18. Moe, W. W. Buying, searching, or browsing: Differentiating between online shoppers using in-store navigational clickstream. Journal of consumer psychology, 13(1-2), 29-39, 2003

19. Bucklin, R. E., \& Sismeiro, C. Click here for Internet insight: Advances in clickstream data analysis in marketing. Journal of Interactive marketing, 23(1), 35-48, 2009 20. Trusov, M., Bodapati, A. V., \& Bucklin, R. E. Determining influential users in internet social networks. Journal of Marketing Research, 47(4), 643-658, 2010

21. Katona, Z., Zubcsek, P. P., \& Sarvary, M. Network effects and personal influences: The diffusion of an online social network. Journal of marketing research, 48(3), 425-443, 2011

22. López García, J. J., Lizcano, D., Ramos, C. M., \& Matos, N. Digital Marketing Actions That Achieve a Better Attraction and Loyalty of Users: An Analytical Study. Future Internet, 11(6), 130, 2019

23. Haenlein, M. Social interactions in customer churn decisions: The impact of relationship directionality. International Journal of Research in Marketing, 30(3), 236-248, 2013

https://www.journals.elsevier.com/journal-of-interactive-marketing

24. Hewett, K., Rand, W., Rust, R. T., \& Van Heerde, H. J. Brand buzz in the echoverse. Journal of Marketing, 80(3), 1-24, 2016

25. Batra, R., \& Keller, K. L. Integrating marketing communications: New findings, new lessons, and new ideas. Journal of Marketing, 80(6), 122-145, 2016

26. Hanssens, D. M., \& Pauwels, K. H. Demonstrating the value of marketing. Journal of Marketing, 80(6), 173-190, 2016

https://www.elsevier.com/about/press-releases/research-and-journals/digital-marketing-

exposure-increases-energy-drink-usage-among-young-adults

https://www.elsevier.com/books/the-digital-consumer-technology-handbook/dhir/978-0-

7506-7815-5

27. Keen, Peter G., Ron Mackintosh, and Mikko Foreword By-Heikkonen. The freedom economy: Gaining the mcommerce edge in the era of the wireless Internet. McGraw-Hill Professional, 2001.

28. Lazovic, Vujica, and Tamara Đuričković. "The digital economy in developing countries-challenges and opportunities." In 2014 37th International Convention on 
Information and Communication Technology, Electronics and Microelectronics (MIPRO), pp. 1580-1585. IEEE, 2014.

29. Leeflang, Peter SH, Peter C. Verhoef, Peter Dahlström, and Tjark Freundt. "Challenges and solutions for marketing in a digital era." European management journal 32, no. 1 (2014): 1-12.

30. Duguleana, L., and C. Duguleana. "Marketing Industry in the Digital Era." In Proceedings of the 6th WSEAS Int. Conference on ENVIRONMENT, ECOSYSTEMS and DEVELOPMENT (EED'08), p. 31. 2008.

31. Nudurupati, Sai S., Sofiane Tebboune, and Julie Hardman. "Contemporary performance measurement and management (PMM) in digital economies." Production Planning \& Control 27, no. 3 (2016): 226-235.

32. Stanković, Jelena, and J. Djorđević-Boljanović. ",Knowledge As a Source of Value in e Process of Marketing Channel Digital Transformation"." In IBC 2012 Internet \& Business Conference, June, pp. 27-28.

33. Owyang, Jeremiah, Christine Tran, and Chris Silva. "The collaborative economy." Altimeter, United States (2013). 